\title{
The Persistence of Traditional Cradle Board (Beshik) Usage among Post-Soviet Central Asian Mothers: Survey Analysis from Southern Kyrgyzstan
}

Global Journal of Social Sciences Studies

Vol. 6, No. 2, 96-105, 2020

e-ISSN: 2518-0614

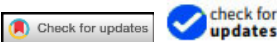

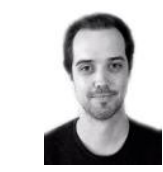

\& Corresponding Author

\author{
Jake Zawlacki ${ }^{1}$
}

(iD) Matthew Derrick ${ }^{2}$

Louisiana State University, Baton Rouge, LA., USA.

Email: jzawla1@lsu.eduTel:6198849497

${ }^{2}$ Humboldt State University, Arcata, CA, USA.

Email:Mattherw.Derrick@humboldt.edu Tel:541860817s

\section{ABSTRACT}

This paper investigates the attitudes, knowledge of, and usage of the traditional Central Asian cradle board (beshik) by Kyrgyzstani mothers residing in the southern region of the Kyrgyz Republic. Socio-economic factors, such as level of education or household income, appear to exert little influence on the likelihood of usage of the traditional Kyrgyz beshik. Rather, dynamics associated with extended family relations appear to be critical in maintaining the practice of infant swaddling long after the widespread cessation of nomadism in the region. Quantitative and qualitative survey data were collected from 481 randomly selected mothers and statistically analyzed to develop an understanding of beshik usage in southern Kyrgyzstan. More than 90\% of the mothers used the traditional Kyrgyz cradle board. The most common reason (33\%) cited by mothers for choosing to use the beshik relates to practicality ("Baby will not get cold"). Mothers opting not to use the cradleboard in childrearing expressed broad skepticism of the beshik, with $38 \%$ responding "All of the above" to a list of five separate options. Knowledge of the effects, beneficial as well as adverse, of swaddling were statistically low among the surveyed mothers: Only $11 \%$ were consulted by a health practitioner about the beshik. If information about the risks of using the cradleboard was provided to new mothers, changes in attitudes regarding the beshik could take place. Based on our data, however, it may have little short-term effect in a region where most mothers adhere closely to the recommendations provided by elders, especially mothers-inlaw.

Keywords: Healthcare, Traditional methods, Cradle board, Beshik, Swaddling, DDH, Developmental dysplasia of the Hip, Plagiocephaly.

DOI: $10.20448 / 807.6 .2 .96 .105$

Citation | Jake Zawlacki; Matthew Derrick (2020). The Persistence of Traditional Cradle Board (Beshik) Usage among Post-Soviet

Central Asian Mothers: Survey Analysis from Southern Kyrgyzstan. Global Journal of Social Sciences Studies, 6(2): 96-105.

Copyright: This work is licensed under a Creative Commons Attribution 3.0 License

Funding: Authors would like to thank the United States Fulbright Program for funding this research project.

Competing Interests: The authors declare that they have no competing interests.

History: Received: 6 July 2020/ Revised: 10 September 2020/ Accepted: 23 September 2020/ Published: 8 October 2020

Publisher: Online Science Publishing 


\section{Highlights of this paper}

- This article investigates Kyrgyz usage statistics of the Central Asian traditional cradle board: the beshik.

- This article examines local knowledge of affiliated diseases with cradle board usage such as Developmental Dysplasia of the Hip (DDH), plagiocephaly, and more.

\section{INTRODUCTION}

The beshik is a Central Asian traditional cradle board used by many in contemporary Kyrgyzstan. The cradle board immobilizes the limbs, protecting the infant from the dangers of nomadic settings, including open fires, domestic animals, and treacherous terrain. Despite the Kyrgyz having transitioned away from a nomadic lifestyle, some nomadic cultural traditions persist (Boyanin, 2011; Yildrim, 2019).

While cradle board usage is popular in Kyrgyzstan (Zawlacki \& Derrick, 2020) it remains an understudied phenomenon. Previous research on health care practices in Kyrgyzstan has focused on the country's post-Soviet transition to a market-based health care system, praising the country for being a "pioneer in reforming the system of health care finance (Falkingham, Akkazieva, \& Baschieri, 2010; Ismailbekova \& Megoran, 2020). Other contributions to the study of health care practices and provisions in contemporary Kyrgyzstan have examined the role of midwives and nurses in providing abortions, contributing to a reduction in the number of unwanted births in the country (Johnson Jr et al., 2018) and the development of palliative care (Mukambetov, Sabyrbekova, Asanalieva, Sadykov, \& Connor, 2019). Shin, Lee, Lee, and Shon (2019) provide a study on community health needs assessment for a child health promotion program in Kyrgyzstan, while Dronina and Nam (2019) published a comparative study of health care systems in Kyrgyzstan, Kazakhstan, and Uzbekistan. Aside from the recent study from Zawlacki and Derrick (2020) however, no health care research has addressed the phenomenon of cradle board usage in post-Soviet Central Asia.

Thus, beshik usage in contemporary Kyrgyzstan presents an interesting case study, as historically the usage of similar cradle boards among peoples in other parts of the world generally ceased once the socio-economics of nomadism gave way to settled lifestyles associated with modernity (Mellbin, 1962; Michelet, 2015).

In our previous work (Zawlacki \& Derrick, 2020) we investigated factors associated with the usage of the beshik among current residents of Bishkek; located in the country's northern region, Bishkek (population 1 million) is the political and economic capital of Kyrgyzstan. Analysis of survey data collected from more than 200 surveys in 2017 indicated that while two-thirds of the respondents reported employing the beshik, the practice was especially prominent among recent immigrants from the less economically developed, more culturally traditional and socially conservative southern region of the country (the north and the south of Kyrgyzstan are bisected by the Tian Shan Mountain Range, forming a physical barrier between the two regions, influencing their separate orientations).

For this article, we turn attention to examination of residents of Osh (population 300,000) and Jalalabad $(100,000)$, the two largest cities in the country's south, seeking a finer-scale examination of the factors driving continued use of the beshik in contemporary Kyrgyzstan. This paper investigates the attitudes, knowledge of, and usage of the traditional Central Asian cradle board (beshik) by Kyrgyzstani mothers residing in the southern region of the Kyrgyz Republic. Modeling the surveys after a previous study of Turkish mothers' attitudes toward swaddling (Yilmaz et al., 2012) we conducted nearly 500 survey questionnaires of mothers of Jalalabad province and Osh province. Socio-economic factors, such as level of education or household income, appear to exert little influence on the likelihood of usage of the traditional Kyrgyz beshik. Rather, dynamics associated with extended family relations appear to be critical in maintaining the practice of infant swaddling long after the widespread cessation of nomadism in the region. 


\section{LITERATURE REVIEW}

Research conducted by Mellbin (1962) indicates that the usage of cradle boards and other infant swaddling techniques were historically practiced among nomadic people across the world, but ceased with cessation of nomadism, i.e. the Sami of northern Scandinavia and the Navajo and Apache Native American tribes (see also (Anzai, Matsuura, Yakubo, Mikami, \& Uemura, 2019; Grove \& Lancy, 2016; Lancy, 2017; Van Sleuwen et al., 2007). While peoples led nomadic lifestyles, such devices were effective in securing infants while adults engaged in highly mobile socio-economic activities. With the transition to settled lifestyles and new socio-economic practices linked to modernization, cradle boards and other swaddling devices proved to be no longer useful and therefore abandoned. However, the practice remains entrenched in small pockets of the globe among formerly nomadic peoples, including residents of contemporary Kyrgyzstan (Michelet, 2015; Nelson, 2017).

Most research on the continued use of the cradle board has approached the topic through the lens of public health because of the associated risk factors (Okka, Durduran, \& KODAZ, 2016; Rabin, Barnett, Arnold, Freiberger, \& Brooks, 1965). Plagiocephaly, the flattening of the head, and developmental dysplasia of the hip (DDH), a congenital hip disorder referring to an abnormality of the pelvis in relation to the femoral head and complete congenital hip dislocation, have both been linked to traditional swaddling techniques similar to the Kyrgyz cradle board (Blatt, 2015; Loder \& Skopelja, 2011; Yang, Zusman, Lieberman, \& Goldstein, 2019). Infants with scoliosis also had a tenfold increased rate of DDH compared to those without (Hooper, 1980). While plagiocephaly is mostly benign in its consequences, DDH often results in a lifelong physical disability lacking a noninvasive solution (Salter, 1968; Sandell, 2012; Weinstein, 1987).

Much of the research on the topic has shifted focus to understanding factors underpinning the continued use of cradle boards in post-nomadic societies. For example, Yilmaz et al. (2012) investigated swaddling practices by contemporary Turkish mothers and their knowledge of possible side effects. In the context of North Africa, studies show that infant swaddling remains prevalent among mothers in rural Jordan, in spite of official campaigns to halt the practice, due to deeply entrenched cultural reasons (Abuidhail, 2014; Al-Sagarat \& Al-Kharabsheh, 2017). Surveying Bishkek, the capital city of Kyrgyzstan, in our previous research (Zawlacki \& Derrick, 2020) we found that mothers who had recently migrated from the southern region of Kyrgyzstan were significantly more likely to use the beshik compared to mothers from the northern region. This finding prompted further investigation into the attitudes and practices of Kyrgyzstani mothers in the most populous cities of the south, Osh and Jalalabad, areas recognized as more culturally traditional than Bishkek and other parts of the country's north (Liu, 2007; Ryan, 2019).

\section{MATERIAL AND METHODS}

Quantitative survey research is among the most common types of research in the field of healthcare and childcare (Aday \& Cornelius, 2006; Kelley, Clark, Brown, \& Sitzia, 2003). Survey questionnaires comprise "one of the most used quantitative techniques (Queirós, Faria, \& Almeida, 2017) due to their comparative advantages, including their relatively quick production of empirical data, ability to capture relatively large samples that may be representative of a much larger population, and, followingly, comparatively low cost for the fast creation of large datasets (Kelley et al., 2003).

However, data derived from quantitative survey questionnaires may be undependable if researchers fail to adhere to certain best practices (Fink, 2015). Among the best practices in survey research, which served as guiding principles in our study, are articulating a clearly defined research question, capturing a large enough sample, fully 
describing the survey instrument, and pretesting and revising the survey instrument (Bennett et al., 2011; Bryson, Turgeon, \& Choi, 2012; Draugalis, Coons, \& Plaza, 2008; Draugalis. \& Plaza, 2009).

The survey questionnaire designed for this project was modeled on the survey instrument used by Yilmaz et al. (2012) in their research on swaddling perceptions among mothers in Turkey. A sample of 481 participants were surveyed between March and May of 2018 in the provinces of Jalalabad and Osh in the south of Kyrgyzstan. Survey participants were randomly approached in public spaces throughout the city centers of each province. Surveys were conducted in Russian, Kyrgyz, and Uzbek languages, depending on the preferred language of the survey participant (Wei, 2008). To decrease potential bias, surveys were conducted by native Kyrgyz research assistants (Wei, 2008).

The following sociodemographic characteristics of the mother were asked in the questionnaire: home location, number of children in the household, years of post-secondary education, language spoken at home, beshik ownership, beshik usage, how many months she swaddled her children in the beshik, and how she learned about using the device. The mother was also asked if she had been consulted by a health professional during pregnancy about swaddling, her age, religion, ethnicity, and type of domicile.

These questions were presented orally to each participant:

1. Where do you live?

2. How many children live in the household?

3. How many years of education do you have?

4. What language is spoken at home?

5. Is there a beshik in your home?

6. Have/will/do you use it?

a. If yes, why?
A Baby will sleep better.
B It is what I learned from my elders.
C Baby will not get cold.
D Baby will cry less and calm down.
E I observed good results from previous children.
F All of the above.
G Others:

b. If not, why not?
A Will increase the risk of hip dysplasia.
B Baby will not pass gas.
C Will increase the risk of sudden infant death syndrome.
D Will increase the risk of lung infection.
E Will prevent normal development.
F Baby's legs will develop irregularly.
G It will be too hot for the baby.
H All of the above.
I Others:

7. If used, how many months did you use the beshik?

8. If used, how did you learn to use the beshik?
A From my elders.
B From my social surroundings. 
C From healthcare workers.

D Via the $\mathrm{TV} /$ internet/media.

E Book.

9. Did a doctor ever mention the beshik to you?

a. If yes, what did s/he say?

10. Would you recommend using the beshik to other mothers?

11. Monthly Income (Kyrgyzstani som)
a. Less than 5,000
b. Between 5,000 and 10,000
c. More than 15,000
d. Pension
e. Decline to answer

12. Age

13. Religion

14. Ethnicity

15. Type of domicile

\section{RESULTS}

The study was conducted on 481 women with ages ranging between 18 and 80 years old (mean=44.6 years). The majority $(54 \%)$ of women surveyed came from medium-income households, 3\% came from low-income households, $18 \%$ were pensioners, and $26 \%$ came from high-income households; $12.7 \%$ participants declined to answer. More than $90 \%$ of the participants stated that they swaddled their babies with the beshik. The majority of participants swaddled their children between 12 and 24 months, $20.6 \%$ swaddled for 12 months, $27.9 \%$ swaddled for 18 months, and $19.8 \%$ swaddled for 24 months; the mean beshik usage time was 18.7 months.

Upon asking what the main reason for using the beshik, just over one-third $(n=144)$ stated it was for practicality ("The baby will not get cold") see Figure 1. Among those electing not to use the beshik, the most common reason $(43.9 \%)$ was "All of the above," indicating the mothers' general distrust of the cradle board see Figure 2.

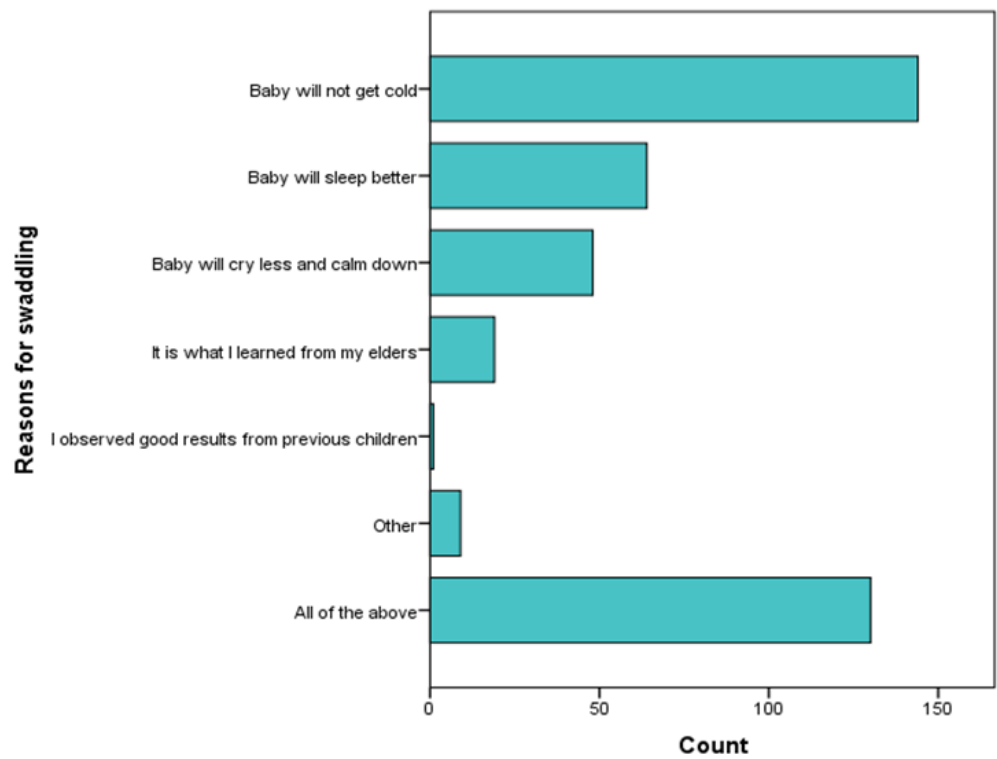

Figure-1. Reasons for swaddling with the beshik. 
Among the survey participants who met with a health practitioner, data suggests ineffective medical consultation. Of the 30 advised not to use the beshik, 24 participants nonetheless did use the cradleboard. Eleven participants were advised to use the beshik, and 10 complied; 14 were given advice to use the beshik with certain conditions, and 13 complied.

Differences between the Jalalabad and Osh provinces were not significant. This likely results from both provinces belonging to part of a larger geographical region in Kyrgyzstan, separated by the Tian Shan Mountain Range from the more economically dynamic, socially mobile, Russified north of the country. The tendency to swaddle had no relationship to age, religion, type of housing, or where in the province the participant lived.

The level of maternal education also was not a significant indicator of whether a mother would use the beshik. Participants with higher levels of education were similarly inclined to swaddle as compared to those with lower levels of education. The rate of swaddling showed no difference by household monthly income.

Participants who used the beshik were asked where they learned about the practice of traditional swaddling. More than 90\% (n=40) stated "From my elders." The second most common response, registered by $7 \%(\mathrm{n}=29)$, was "From my social surroundings." These results suggest a strong influence of elders.

No demographic study has been conducted among the Kyrgyz population elucidating factors for the usage of the traditional cradleboard. Furthermore, there exists no recorded data of usage statistics across any of the postSoviet Central Asian countries: Kyrgyzstan, Kazakhstan, Turkmenistan, Uzbekistan, and Tajikistan. Our research is the first of its kind in addressing a traditional medical practice that has been overlooked by scholars and medical researchers alike in studying Developmental Dysplasia of the Hip (DDH). Even among scholarship addressing traditional nomadic practices (Loder \& Skopelja, 2011) we found no mention of cradleboard usage in the steppe nomad tradition.

This article hopes to help build a foundation of research for further exploration into not only the influences on those who use traditional health practices, but on how to prepare medical professionals with training and education for the specific risks associated with the traditional Central Asian cradleboard. While this region of the world is most certainly a lacuna in the global discussion of $\mathrm{DDH}$, we hope to provide meaningful data to future researchers and scholars.

\section{DISCUSSION}

With the foregoing in mind, we frame this discussion around two main takeaways for medical researchers. First, a significant finding of our research relates to health education and doctor consultation in south Kyrgyzstan. Only $11.4 \%$ (55 of 481) received a doctor's consultation about the beshik. Thirty of the consultations explicitly advised against using the cradle board, yet only six participants reported complying with that recommendation. That such a small number received doctor's advice against using the beshik suggests that the region's medical community is not communicating best practices in childcare.

Indeed, even those respondents who chose not to use the beshik were unable to clearly explain why see Figure 2. None of the 47 participants not employing the beshik mentioned the risk of Developmental Dysplasia of the Hip or plagiocephaly, the two most common risks of using nomadic cradleboards. Among the few concrete reasons against usage, as expressed by our participants, was "Doctors said legs won't be straight," a medical concern unrelated to what are far and away the two most common risks. Other reasons for not using the device included "The beshik is uncomfortable" and "Doctor said to be careful," concerns ungrounded in best medical practice. The lack of evidencebased reasons suggests a need for beshik-specific health education for health professionals and mothers alike. 


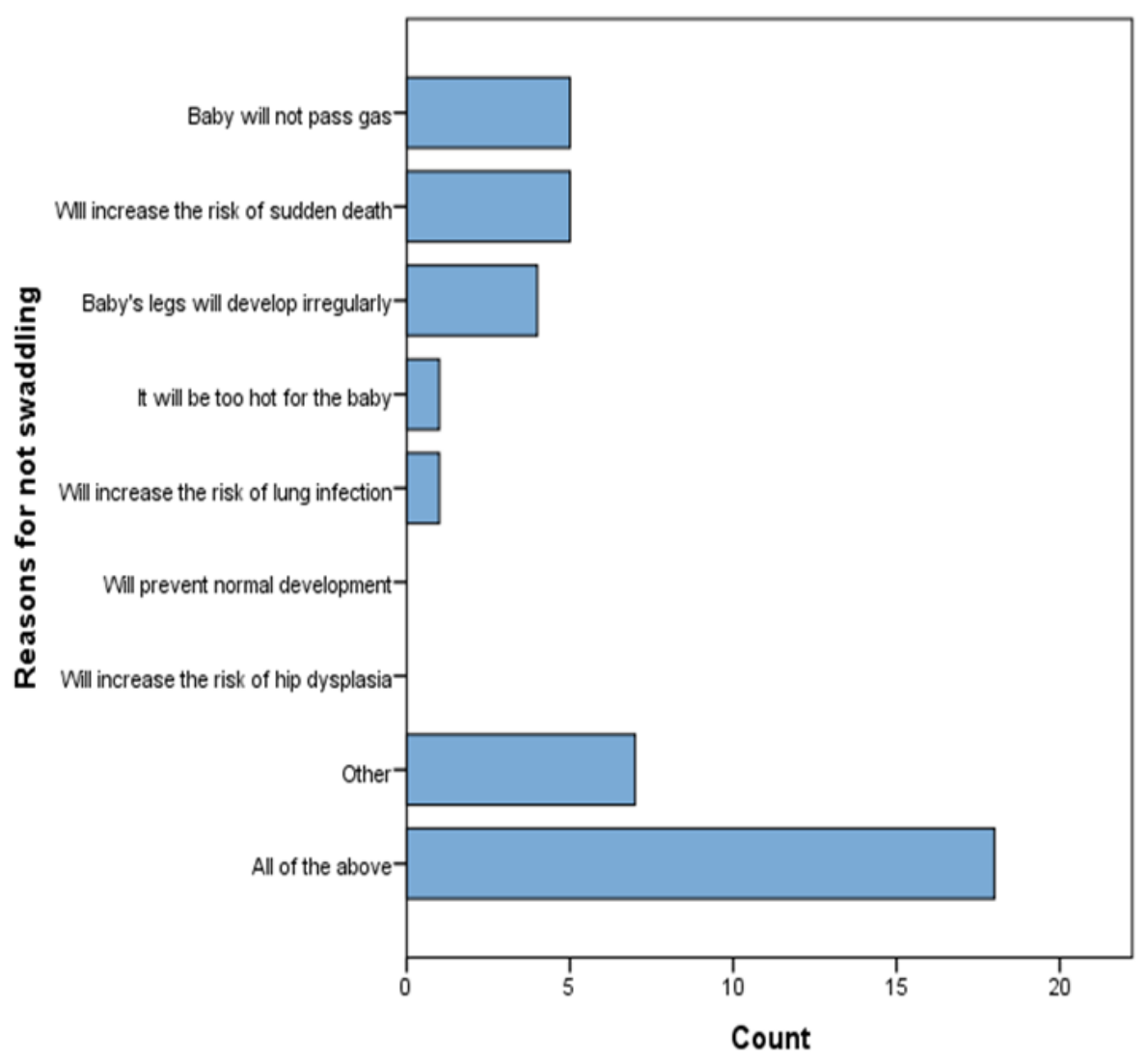

Figure-2. Reasons for not swaddling with the beshik.

As a second takeaway for medical researchers, our analysis of data from the small subset of non-Kyrgyz/nonUzbek survey participants $(n=43)$ provides some insight into the complexities of ethnic identities and the influence of traditional family structures. Nearly $60 \%(\mathrm{n}=22)$ of this subset said "yes" to using the beshik, significantly lower in portion compared to the overall figure of $90 \%$. However, a mother's choice is clearly influenced by ethnic heritage. All Turkic peoples in this subset reported using the cradleboard: Turks ( $\mathrm{n}=7)$, Kazakhs $(\mathrm{n}=3)$, and Uyghurs ( $\mathrm{n}=1)$. The sole Tajik participant also reported using the beshik. Half the Chinese ( 2 of 4 ) and half the Dungans ( 1 of 2 ), closely related ethnic groups cleaved by traditional religious affiliation (unlike Han Chinese, Dungans are historically associated with Islam), utilized the cradleboard.

In the non-Kyrgyz/non-Uzbek subset, Russians $(n=16)$ and Ukrainians $(n=3)$ together represent the group's Slavic contingency. Yet they diverge in their choice in cradleboard usage. None of the Ukrainian mothers used the beshik. Ethnic Russians, however, displayed a more complex relationship to the cradleboard. Of the 16 Russian mothers, seven used the beshik, while nine did not. One explained her decision not to use the cradleboard in simple ethnic terms: "Russians don't use them.” However, she is contradicted by two other Russian mothers who explained why they did use the beshik: "Because my mother-in-law [either Kyrgyz or Uzbek] told me to."

Our previous research in Bishkek (Zawlacki \& Derrick, 2020) identified Russification to be the strongest factor in determining if a Kyrgyz mother would use the beshik. That $44 \%(n=7)$ of the Russian mothers in Osh/Jalalabad used the traditional cradleboard on their children suggests that the process of acculturation, at least in the question of beshik usage, is not unidirectional. In Kyrgyzstan's south, a Russian mother's decision to use the cradleboard is intertwined with her entry into the traditional family structures of the region's ethnic Kyrgz and Uzbeks. In these family structures, the elder mother exerts great influence within the domestic sphere which she shares closely with her daughter-in-law (Childress, 2018; Ismailbekova, 2016; Ismailbekova \& Megoran, 2020). 


\section{CONCLUSION}

Prior to this study, based on our database searches, no demographic study has been conducted among the Kyrgyz population elucidating factors for the usage of the traditional cradleboard. Furthermore, we uncovered no recorded data of usage statistics across any of the post-Soviet Central Asian countries: Kyrgyzstan, Kazakhstan, Turkmenistan, Uzbekistan, and Tajikistan. Our research is the first of its kind in addressing a traditional medical practice that has been overlooked by scholars and medical researchers alike in studying Developmental Dysplasia of the Hip (DDH). Even among scholarship addressing traditional nomadic practices (Loder \& Skopelja, 2011) we found no mention of cradleboard usage in the steppe nomad tradition.

This data is meant to be a starting point for further research in the usage demographics of the Central Asian traditional cradleboard. In order to further address the increased rate of DDH among Central Asian populations and recommend possible solutions, additional statistics with varying population samples must be collected. As our research has shown, the usage of the beshik shows no signs of slowing down. For this practice to continue, greater awareness on part of health practitioners must be founded in additional research findings. Until then, the beshik will continue to be used as it has for thousands of years without the proper sensitivity by health professionals to screen for the disease in infancy.

\section{ACKNOWLEDGEMENTS}

The authors would like to acknowledge Aiperi Sulaimanova and Eliza Kanzharbekova for their essential contributions to this research.

\section{REFERENCES}

Abuidhail, J. (2014). Rural Jordanian mothers' beliefs, knowledge and practices of postnatal care. Quality in Primary Care, 22(6), 285-293.

Aday, L. A., \& Cornelius, L. J. (2006). Designing and conducting health surveys: A comprehensive guide (3rd ed.). San Francisco, CA: Jossey-Bass

Al-Sagarat, A. Y., \& Al-Kharabsheh, A. (2017). Traditional practices adopted by Jordanian mothers when caring for their infants in rural areas. African Journal of Traditional, Complementary and Alternative Medicines, 14(1), 1-9.Available at: https://doi.org/10.21010/ajtcam.v14i1.1.

Anzai, T., Matsuura, K., Yakubo, T., Mikami, T., \& Uemura, K. (2019). Health education that breaks through language barriers: Prototyping and evaluation of childcare-related ICT self-learning resources. Design and Living Well: Re: Research, 4(1), 63-76.

Bennett, C., Khangura, S., Brehaut, J. C., Graham, I. D., Moher, D., Potter, B. K., \& Grimshaw, J. M. (2011). Reporting guidelines for survey research: An analysis of published guidance and reporting practices. PLoS Med, 8(8), e1001069.Available at: https://doi.org/10.1371/journal.pmed.1001069.

Blatt, S. H. (2015). To swaddle, or not to swaddle? paleoepidemiology of developmental dysplasia of the hip and the swaddling dilemma among the indigenous populations of N orth A merica. American Journal of Human Biology, 27(1), 116128.Available at: https://doi.org/10.1002/ajhb.22622.

Boyanin, Y. (2011). The kyrgyz of naryn in the early soviet period: A study examining settlement, collectivisation and dekulakisation on the basis of oral evidence. Inner Asia, 13(2), 279-296.Available at: https://doi.org/10.1163/000000011799297582.

Bryson, G. L., Turgeon, A. F., \& Choi, P. T. (2012). The science of opinion: survey methods in research. Canadian Journal of Anesthesia/Journal canadien d'anesthésie, 59(8), 736-742. 
Childress, S. (2018). "Plates and dishes smash; married couples clash": Cultural and social barriers to help-seeking among women domestic violence survivors in Kyrgyzstan. Violence Against Women, 24(7), 775-797.Available at: https://doi.org/10.1177/1077801217722239.

Draugalis, J., Coons, S., \& Plaza, C. (2008). Best practices for survey research reports: A synopsis for authors and reviewers. American Journal of Pharmaceutical Education, 72(1), 11-11.Available at: https://doi.org/10.5688/aj720111.

Draugalis., J. R., \& Plaza, C. M. (2009). Best practices for survey research reports revisited: Implications of target population, probability sampling, and response rate. American Journal of Pharmaceutical Education, 73(8), 1-3.

Dronina, Y., \& Nam, E. W. (2019). Comparative study of health care system in three central Asian countries: Kazakhstan, Kyrgyzstan, Uzbekistan. Journal of Health Administration, 29(3), 342-356.

Falkingham, J., Akkazieva, B., \& Baschieri, A. (2010). Trends in out-of-pocket payments for health care in Kyrgyzstan, 20012007. Health Policy and Planning, 25(5), 427-436.Available at: https://doi.org/10.1093/heapol/czq01 1.

Fink, A. (2015). How to conduct surveys: A step-by-step guide. Los Angeles, CA: Sage Publications.

Grove, M. A., \& Lancy, D. F. (2016). Cultural models of stages in child development. In Gielen, U.P., \& Roopnarine, J.L. (Eds.), Childhood and adolescence: Cross-cultural perspectives and applications (pp. 47-62). Santa Barbara, CA: Praeger.

Hooper, G. (1980). Congenital dislocation of the hip in infantile idiopathic scoliosis. The Journal of bone and joint surgery. British volume, 62(4), 447-449.

Ismailbekova, A. (2016). Constructing the authority of women through custom: Bulak village, Kyrgyzstan. Nationalities Papers, 44(2), 266-280.Available at: https://doi.org/10.1080/00905992.2015.1081381.

Ismailbekova, A., \& Megoran, N. (2020). Peace in the family is the basis of peace in the country: How women contribute to local peace in Southern Kyrgyzstan. Journal of Intervention and Statebuilding, 14(4), 483-500.Available at: https://doi.org/10.1080/17502977.2020.1780017.

Johnson Jr, B. R., Maksutova, E., Boobekova, A., Davletova, A., Kazakbaeva, C., Kondrateva, Y., . . Jo, A. H. S. (2018). Provision of medical abortion by midlevel healthcare providers in Kyrgyzstan: testing an intervention to expand safe abortion services to underserved rural and periurban areas. Contraception, 97(2), 160-166.Available at: https://doi.org/10.1016/j.contraception.2017.11.002.

Kelley, K., Clark, B., Brown, V., \& Sitzia, J. (2003). Good practice in the conduct and reporting of survey research. International Journal for Quality in health care, 15(3), 261-266.Available at: https://doi.org/10.1093/intqhe/mzg031.

Lancy, D. F. (2017). Raising children: Surprising insights from other cultures. Cambridge, UK: Cambridge University Press.

Liu, M. Y. (2007). A Central Asian tale of two cities: Locating lives and aspirations in a shifting post-Soviet cityscape. In Montgomery, D.W. (Ed.), Everyday life in Central Asia: Past and present (pp. 66-83). Bloomington, IN: Indiana University Press.

Loder, R. T., \& Skopelja, E. N. (2011). The epidemiology and demographics of hip dysplasia. International Scholarly Research Notices, 2011, 46.Available at: https://doi.org/10.5402/2011/238607.

Mellbin, T. (1962). The children of Swedish nomad lapps. VII. Congenital malformations. Acta Orthopaedica Scandinavica, 131(1), 62-66.

Michelet, A. (2015). Why are mongolian infants treated like 'kings'?: Care practices and multifaceted personhood of young children in the Middle Gobi (Mongolia). Inner Asia, 17(2), 273-292.

Mukambetov, A., Sabyrbekova, T., Asanalieva, L., Sadykov, I., \& Connor, S. R. (2019). Palliative care development in Kyrgyzstan. Journal of Pain and Symptom Management, 55(2), 41-45.

Nelson, A. M. (2017). Risks and benefits of swaddling healthy infants: An integrative review. MCN: The American Journal of Maternal/Child Nursing, 42(4), 216-225.Available at: https://doi.org/10.1097/nmc.0000000000000344. 
Okka, B., Durduran, Y., \& KODAZ, N. D. (2016). Traditional practices of Konya women during pregnancy, birth, the postpartumperiod, and newborn care. Turkish journal of medical sciences, 46(2), 501-511.Available at: https://doi.org/10.3906/sag-1504-120.

Queirós, A., Faria, D., \& Almeida, F. (2017). Strengths and limitations of qualitative and quantitative research methods. European Journal of Education Studies, 3(9), 369-387.

Rabin, D. L., Barnett, C. R., Arnold, W. D., Freiberger, R. H., \& Brooks, G. (1965). Untreated congenital hip disease: A study of the epidemiology, natural history, and social aspects of the disease in a Navajo population. American Journal of Public Health and the Nations Health, 55(Suppl_2), i3-44.Available at: https://doi.org/10.2 105/ajph.55.suppl_2.i3.

Ryan, C. M. (2019). Urban transformation, conflict and everyday life in Osh, Kyrgyzstan: From socialist legacy to territorializations of history and memory. Doctoral dissertation, University of Colorado at Boulder.

Salter, R. B. (1968). Etiology, pathogenesis and possible prevention of congenital dislocation of the hip. Canadian Medical Association Journal, 98(20), 933.Available at: https://doi.org/10.1007/978-3-642-71038-4_5.

Sandell, L. J. (2012). Etiology of osteoarthritis: Genetics and synovial joint development. Nature Revierws Rheumatology, 8(2), 7789.

Shin, H., Lee, S. J., Lee, Y.-n., \& Shon, S. (2019). Community health needs assessment for a child health promotion program in Kyrgyzstan. Evaluation and Program Planning, 74(C), 1-9.Available at: https://doi.org/10.1016/j.evalprogplan.2019.02.005.

Van Sleuwen, B. E., Engelberts, A. C., Boere-Boonekamp, M. M., Kuis, W., Schulpen, T. W., \& L'Hoir, M. P. (2007). Swaddling: A systematic review. Pediatrics, 120(4), e1097-e1 106.Available at: https://doi.org/10.1542/peds.2006-2083.

Wei, L. (2008). Research perspectives on bilingualism and multilingualism. In Wei, L., \& Moyer, M.G. (Eds.), The Blackwell guide to research methods in bilingualism and multilingualism (pp. 3-17). Malden, MA: John Wiley \& Sons.

Weinstein, S. L. (1987). Natural history of congenital hip dislocation (CDH) and hip dysplasia. Clinical Orthopaedics and Related Research ${ }^{\circledR}, 225,62-76$.

Yang, S., Zusman, N., Lieberman, E., \& Goldstein, R. Y. (2019). Developmental dysplasia of the hip. Pediatrics, 143(1), 1-12.

Yildrim, S. (2019). Post-Soviet migration patterns in Kyrgyzstan and the case of Uzbels. Doctoral dissertation, Middle East Technical University.

Yilmaz, A., Unsal, N., Celik, N., Karabel, M., Keskin, E., Tan, S., \& Aldemir, S. (2012). A perspective from the practice of swaddling by Turkish mothers. Hippokratia, 16(2), 130-136.

Zawlacki, J., \& Derrick, M. (2020). An examination of contemporary use of the traditional nomadic infant cradle board (beshik) among the Kyrgyz of Bishkek, Kyrgyzstan. International Journal of Russian Studies, 9(1), 64-79. 